\title{
Bringing back the doctors' lounge to help fight burnout
}

— Cite as: CMAJ 2019 March 4;191:E268-9. doi: 10.1503/cmaj.109-5714

Posted on cmajnews.com on Feb. 13, 2019.

pace to think. A place to relax, unwind, catch up with co-workers. Years ago, the doctors' lounge was that sanctuary, a dedicated area in every hospital for physicians who needed a moment of respite. Over the years, however, many of these lounges have disappeared, casualties of cost-cutting and hospital overcrowding.

But appreciation for the doctors' lounge is on the upswing. A recent article in $B M J$ highlighted the work of two pediatrics trainees in the United Kingdom who made it their mission to revitalize their doctors' lounge. Their rationale? "We are so good at constantly putting ourselves second, and we thought, 'You know what, we're going to put ourselves first."'

Their focus on the importance of the lounge to physician well-being dovetails with the British Medical Association's Fatigue and Facilities Charter, released in March 2018. One of the key demands of the charter, aimed at improving doctors' working environments, was to create better common rooms or lounges.

In Canada, a national survey in 2018 by the Canadian Medical Association reported that about a third of Canadian doctors were burned out or depressed. It noted that most efforts to prevent burnout have focused on improving personal resiliency rather than workplaces and training environments.

That may change as more data come in supporting the importance of the physical workplace to doctors' well-being. In 2017, the American Medical Association published an interview with Dr. Diane Sliwka, a hospitalist and professor of medicine at the University of California, San Francisco (UCSF), who spearheaded the reinstatement of a modern doctors' lounge at her hospital to help battle burnout.

"When we surveyed our own physician work experience, we found a need people kept bringing up was that there wasn't a space for physicians to come together and

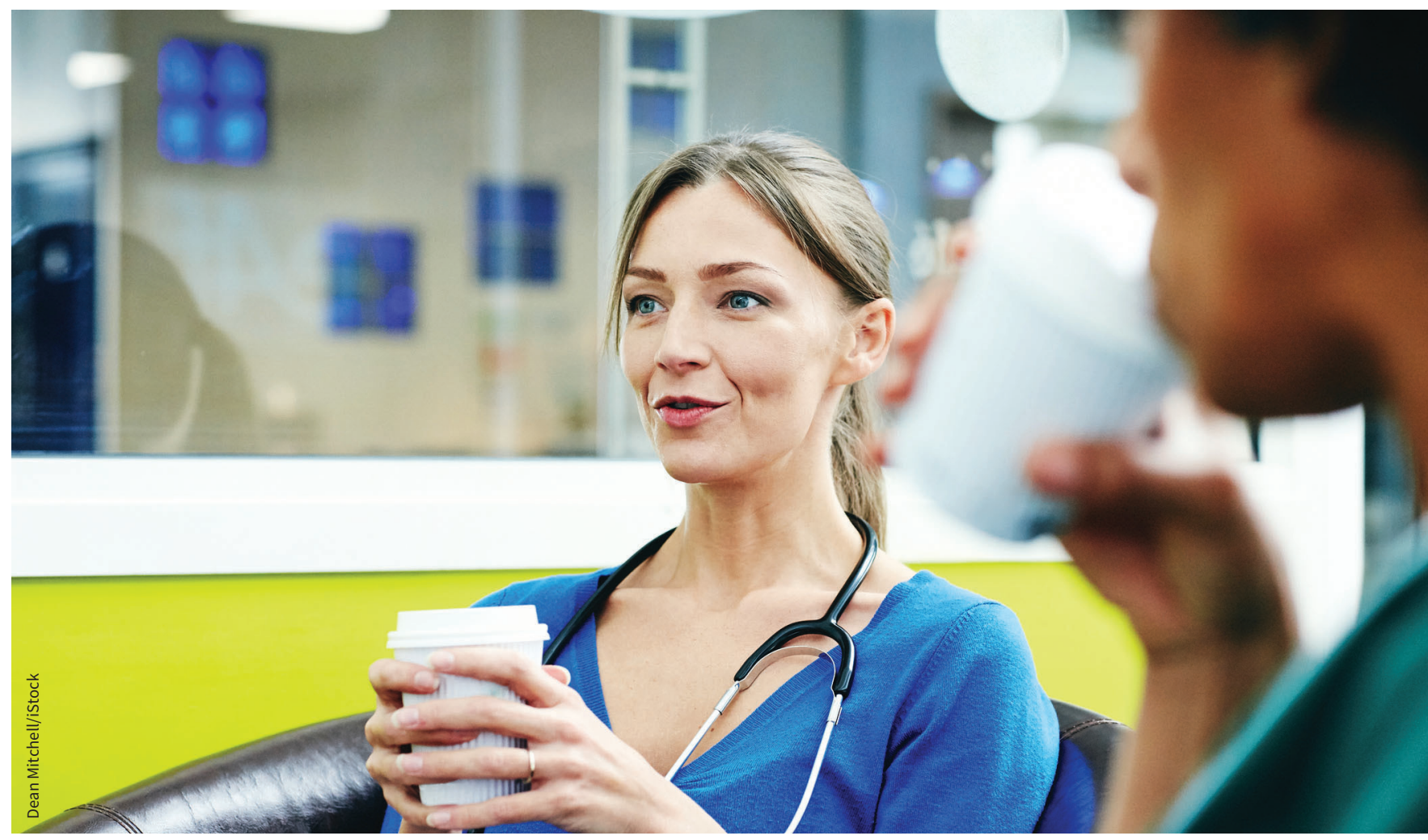

Many doctors' lounges have disappeared because of cost-cutting and hospital overcrowding. 
get away from the action of work," Sliwka noted. Though the UCSF lounge had great amenities - workstations, comfortable sofas, and refreshments - she posited that its greatest value was allowing physicians to become reacquainted with their colleagues and feel a sense of connectedness.

Sliwka's position is backed up by two recent essays in the New England Journal of Medicine. In "Navigating Loneliness in the Era of Virtual Care," Dr. Ameya Kulkarni explored physicians' need for meaningful interaction with their colleagues and lamented a reality in which "painful moments are no longer eased by shared experience."

In "RVU [relative value unit] Medicine, Technology, and Physician Loneliness," Dr. Richard Wenzel wrote of discovering the value of the half-hour ritual of tea time while on sabbatical at the London School of Hygiene and Tropical Medicine in the 1980s. Though initially skeptical of the practice, he soon discovered that, when his colleagues made time to get together, "conversations flowed, ideas were exchanged, mentoring flourished, and perhaps most important, trust grew." When he returned to the United States, he lobbied for a faculty dining room and retreat centre in his own place of work.

Dr. Ken Flegel, a specialist in internal medicine at Montreal's Royal Victoria Hospital and senior associate editor at CMAJ, speaks from long experience when he calls the demise of the doctors' lounge "a real loss." (A doctors' lounge did not make the cut when the storied Royal Vic moved to its new location in 2015.)

For Flegel, the lounge served many functions over the years. As a young attending physician in 1979, he took advantage of the lounge as a place to meet physicians in other specialties, get referrals, and ask questions on behalf of his patients. He also met mentors who taught him how to be a better physician. "The lounge was a long tutorial that allowed me to learn how to be a human as well as a specialist. I learned from having the opportunity in the lounge to watch, listen, and talk to these older physicians."

Years later, as an experienced physician, he visited the lounge to relax, socialize, and discuss strategies for difficult cases. With the lounge gone, he misses the camaraderie, but also the professional confidence that comes with knowing all his colleagues. "I'm sending my patients to surgeons who I don't know. To me, that's sad. It's just not a good feeling."

Sarah Brown, Ottawa, Ont. 